\title{
Determination of Intramolecular Hydrogen Bonds and Selective Coordination of Sodium Cation in Alkalicellulose by $\mathrm{CP} / \mathrm{MASS}{ }^{13} \mathrm{C}$ NMR
}

\author{
Kenji KAMIDE, Keisuke KowsaKA, and Kunihiko OKaJIMA \\ Textile Research Laboratories, Asahi Chemical Industry Co., Ltd., \\ Hacchonawate 11-7, Takatsuki, Osaka 569, Japan
}

(Received September 5, 1984)

\begin{abstract}
Alkalicellulose, prepared from wood pulp, was analyzed using CP/MASS ${ }^{13} \mathrm{C}$ NMR. In the alkalicellulose I solid, molecular motion is more rapid than that in the cellulose I solid and there is an intramolecular hydrogen bond between the hydroxyl at $\mathrm{C}_{3}$ and ring oxygen $\mathrm{O}_{5}^{\prime}$, which is slightly weaker than that for cellulose I. A sodium ion was found to selectively coordinate to the hydroxyl oxygen at the $\mathrm{C}_{2}$ position of the glucose unit.

KEY WORDS Alkalicellulose / CP/MASS ${ }^{13} \mathrm{C}$ NMR / Cellulose / Intramolecular Hydrogen Bond / Cellulose I /
\end{abstract}

Alkalicellulose is chemically highly reactive so that cellulose ethers, such as carboxymethylcellulose, hydroxyethylcellulose, hydroxypropylcellulose, methylcellulose, ethylcellulose and their coethers, are at present commercially synthesized on a large scale via alkalicellulose as an intermediate compound from cellulose. Various crystal forms including alkalicellulose I, II, III, and IV have been found to exist by X-ray diffraction method and for each from the chemical composition of the sodium ion $\mathrm{Na}^{+}$, water and anhydrous glucose unit was determined by the chemical analysis. ${ }^{1-4}$

It is widely recognized that the reactivity of alkalicellulose against other chemical reagent and the distribution of substituent groups of cellulose derivatives formed thus depend remarkably on the solid state structure (crystal form, crystallinity and morphology) of alkalicellulose. Alkalicellulose I (Nacell-I) readily reacts with carbon disulfide to give cellulose xanthate and the ratio of the probability of carboxymethylation at the hydroxyl group attached to $C_{6}$ position $\left\langle\mathrm{f}_{6}\right\rangle$, to that of total degree of substitution $\langle\mathrm{F}\rangle$ depends on the crystal form of the starting cellulose, if the operating conditions of carboxymethylation reaction are kept the same. ${ }^{5}$

However, there are unfortunately only few methods available to obtain directly detailed information on the chemical structure of cellulose solid. Wide-angle X-ray diffraction provides information only on the crystal structure.

Recently, we demonstrated that CP/MASS ${ }^{13} \mathrm{C}$ NMR technique is particularly useful to analyze the hydrogen bonds of a cellulose solid, and concluded that the intramolecular hydrogen bond plays an important role in the solubility of cellulose in dilute alkali. ${ }^{6}$ Applying the same technique to alkalicellulose, Kunze et al..$^{7,8}$ demonstrated, although very qualitatively due to the low resolving of their NMR spectra, the change in the crystal form with alkali concentration.

In this article, an attempt is made to clarify, using CP/MASS ${ }^{13} \mathrm{C}$ NMR, whether the intramolecular hydrogen bond and selective coordination of $\mathrm{Na}^{+}$exist in Nacell-I, prepared by dipping cellulose $\mathrm{I}$ in a $18 \mathrm{wt} \%$ 
aqueous sodium hydroxide solution.

\section{EXPERIMENTAL}

\section{Cellulose}

Wood pulp (C-1) having the viscosityaverage molecular weight $M_{v}=2.1 \times 10^{5}$ and crystal form of cellulose I was employed. Here, $M_{v}$ was determined from the limiting viscosity number $[\eta]$ in cadoxen solution using BrownWikstrom's equation, ${ }^{9}[\eta]=3.85 \times 10^{-2} M_{w}^{0.76}$ at $25^{\circ} \mathrm{C}$.

\section{Alkalicellulose}

A 100 weight part of cellulose was immersed in a 2000 weight part of a $18 \mathrm{wt} \%$ aqueous sodium hydroxide solution at $30^{\circ} \mathrm{C}$ for $30 \mathrm{~min}$ and then pressed between polyacrylonitrile cloth and cellulose filter paper by a hand press to give $c a$. a 280 weight part of alkalicellulose. Alkalicellulose thus prepared was referred to as $\mathrm{AC}-1$. AC-1 was crushed in a mixer so that its apparent specific volume became $15 \mathrm{ml} \mathrm{g}^{-1}$. $\mathrm{AC}-1$ and stored in a closed vessel containing air at $49^{\circ} \mathrm{C}$ for $30 \mathrm{~h}$. The sample thus aged was referred to as AC-Ia.

\section{$C P / M A S S{ }^{13} C N M R$}

The NMR spectra were obtained on a JEOL FX-200 type FT-NMR spectrometer, using a cross polarization (CP)/dipole decoupled (DD)/magic angle sample spinning (MASS) technique: CP contact time $2 \mathrm{~ms}$, repetition time $5 \mathrm{~s}$, measuring temperature $50-80^{\circ} \mathrm{C}$.
Sample code AC-1 was measured immediately after sample preparation and sample code ACla, after aging.

\section{RESULTS}

Figure 1 shows the CP/MASS NMR spectra of cellulose sample C-1 (Figure 1a), cited from the previous paper ${ }^{10}$ and of its alkali celluloses

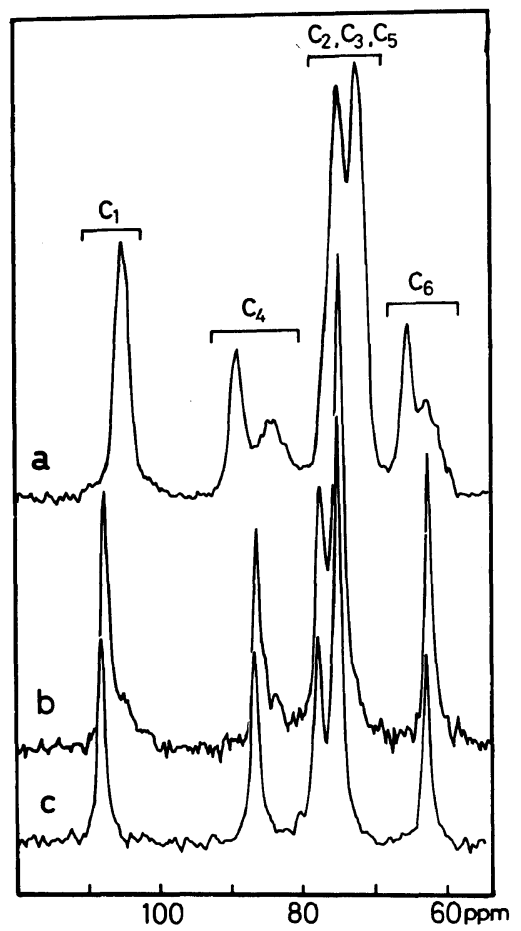

Figure 1. $\mathrm{CP} / \mathrm{MASS}{ }^{13} \mathrm{C}$ NMR spectra of cellulose I and alkalicelluloses. a, cellulose I (C-1); b, alkalicellulose without aging (AC-1); c, aged alkalicellulose (AC-1a).

Table I. Peak assignment of cellulose and alkali cellulose

\begin{tabular}{|c|c|c|c|c|c|c|c|c|}
\hline \multirow{3}{*}{$\begin{array}{l}\text { Samples } \\
\text { C-1 }\end{array}$} & \multicolumn{8}{|c|}{ Carbon position/ppm } \\
\hline & \multirow{2}{*}{\begin{tabular}{cc}
\multicolumn{2}{c}{$\mathrm{C}_{1}$} \\
$105.4^{\mathrm{b}}$ & \\
$(1.00)$ & \\
107.8 & $105.3^{\mathrm{s}}$
\end{tabular}} & \multicolumn{3}{|c|}{$\mathrm{C}_{4}$} & \multicolumn{2}{|c|}{$\mathrm{C}_{2}, \mathrm{C}_{3}, \mathrm{C}_{5}$} & \multicolumn{2}{|c|}{$\mathrm{C}_{6}$} \\
\hline & & $\begin{array}{c}89.1 \\
(0.47)\end{array}$ & $\begin{array}{c}84.5^{b} \\
(0.53)\end{array}$ & & $\begin{array}{c}75.3 \\
(1.57)\end{array}$ & $\begin{array}{c}72.2 \\
(1.51)\end{array}$ & $\begin{array}{c}65.5 \\
(0.55)\end{array}$ & $\begin{array}{c}63.0^{\mathrm{b}} \\
(0.38)\end{array}$ \\
\hline $\mathrm{AC}-1$ & ${ }_{(1.00)}^{107.8}$ & ${ }^{86.4}$ & $85.4^{\mathrm{s}}$ & $\begin{array}{r}83.8^{\mathrm{b}} \\
(0.29)\end{array}$ & $\begin{array}{c}77.7 \\
(0.98)\end{array}$ & $\begin{array}{l}74.9 \\
(2.10)\end{array}$ & $\begin{array}{c}62.8 \\
(0.98)\end{array}$ & \\
\hline AC-1a & $\begin{array}{l}108.3 \\
(1.00)\end{array}$ & $\begin{array}{c}86.8 \\
(1.02)\end{array}$ & & & $\begin{array}{c}78.0 \\
(1.10)\end{array}$ & $\begin{array}{c}75.1 \\
(2.10)\end{array}$ & $\begin{array}{c}63.0 \\
(0.98)\end{array}$ & \\
\hline
\end{tabular}

b denotes broad peak, $\mathrm{s}$, shoulder peak and the value in parenthesis are peak intensities. 
AC-1 and AC-1a (Figures $1 \mathrm{~b}$ and c, respectively). Table I shows the peak positions (TMS as reference material) and integrated peak intensity (in blanket) of NMR spectra in Figure 1. Suffix $b$ refers to a broad peak.

The half-value width of all NMR peaks of alkalicellulose was only $1 / 2-1 / 4$ that of cellulose. The peak positions of cellulose were almost similar with those for alkalicellulose. Peaks at $108,90-80$, and $63 \mathrm{ppm}$ were assigned for $\mathrm{C}_{1}, \mathrm{C}_{4}$, and $\mathrm{C}_{6}$ carbons. In Figure 1 , the $\mathrm{C}_{1}$ and $\mathrm{C}_{4}$ carbon peaks for $\mathrm{AC}$-1a are seen as singlet at 108.3 and 86.3 ppm, respectively. But AC-1 sample has a small higher field component in both the $\mathrm{C}_{1}$ and $\mathrm{C}_{4}$ carbon peak regions, showing $\mathrm{AC}-1 \mathrm{a}$ have weaker parts in intramolecular hydrogen bonding compared with that of $\mathrm{AC}-1$.

\section{DISCUSSION}

From Figure 1, it is obvious that the $\mathrm{C}_{4}$ and $\mathrm{C}_{6}$ carbon peaks for cellulose show broad distribution depending on the wide distribution of the bond strength of the intramolecular hydrogen bond (Figure 1a). In contrast, all carbon peaks for alkalicellulose are simple and sharp (Figures $1 \mathrm{~b}$ and 1c). This is particularly apparent in AC-1a. This strongly suggests that in alkalicellulose, the distance between molecular chains is so widened due to swelling action of alkali against cellulose that as many conformations of glucoside linkage as that in solution are possible and the rate of interconversion of these conformations is relatively rapid. This leads to a single and sharp time-averaged NMR peak (i.e., AC-1a) due to each carbon's relaxation time. In this sense, alkalicellulose has the uniform solid structure. Each carbon peak position does not always coincide with that for cellulose dissolved in aq. sodium hydroxide. The $\mathrm{C}_{4}$ carbon peak in solution, where $\mathrm{O}_{3}-\mathrm{H} \cdots \mathrm{O}_{5}^{\prime}$ intramolecular hydrogen bonds are considered to be completely broken, resonates at $c a .80 \mathrm{ppm},{ }^{6}$ and the corresponding peak, originating from the
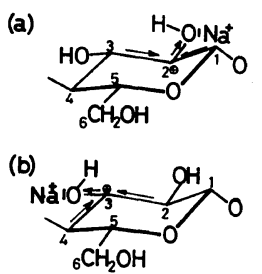

(c)

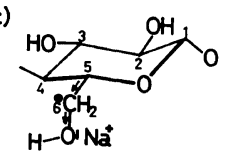

Figure 2. Possible chemical structure of alkalicellulose. Alkalicellulose with selective coordination of a sodium ion to the hydroxyl oxygen at the $\mathrm{C}_{2}(\mathrm{a}), \mathrm{C}_{3}(\mathrm{~b})$, and $\mathrm{C}_{6}$ (c) positions; arrow mark denotes location of electron.

region in which the intramolecular hydrogen bonds are strongly formed, is observed at $89 \mathrm{ppm}$. The $\mathrm{C}_{4}$ carbon peak of alkalicellulose is observed at $86-87 \mathrm{ppm}$. These experimental facts show that even in alkalicellulose, there exist weak intramolecular hydrogen bonds.

$\mathrm{C}_{1}$ carbon peak of cellulose varies between 104 and $106 \mathrm{ppm}$, depending on the strength of $\mathrm{O}_{3}-\mathrm{H} \cdots \mathrm{O}_{5}^{\prime}$ intramolecular hydrogen bonds. ${ }^{10}$ Unexpectedly, the $\mathrm{C}_{1}$ carbon peak of alkalicellulose is sharp at $108 \mathrm{ppm}$ and significantly outside the possible variation of the $\mathrm{C}_{1}$ carbon peak of cellulose. This must be explained on a basis other than the intramolecular hydrogen bonding. This situation is the same for the peak at 78 ppm for alkalicellulose. To explain the appearance of this peak, the abstruction of an electron from the carbon adjacent to the hydroxyl group, induced by selective coordination of $\mathrm{Na}^{+}$ to the hydroxyl group, should be considered. As is well-known, alkalicellulose $I$ has the chemical composition of $\mathrm{C}_{6} \mathrm{H}_{10} \mathrm{O}_{5} \cdot \mathrm{NaOH}$. $3 \mathrm{H}_{2} \mathrm{O}$, meaning that $\mathrm{Na}^{+}$is coordinated to a glucose ring. Figure 2 shows the possible chemical structure of alkalicellulose I when $\mathrm{Na}^{+}$is selectively coordinated to the hydroxyl groups at $\mathrm{C}_{2}, \mathrm{C}_{3}$, and $\mathrm{C}_{6}$, respectively. Whether the states shown in Figure 2 are stable as alcoholates is not clear, but the electron density on the carbons located at 


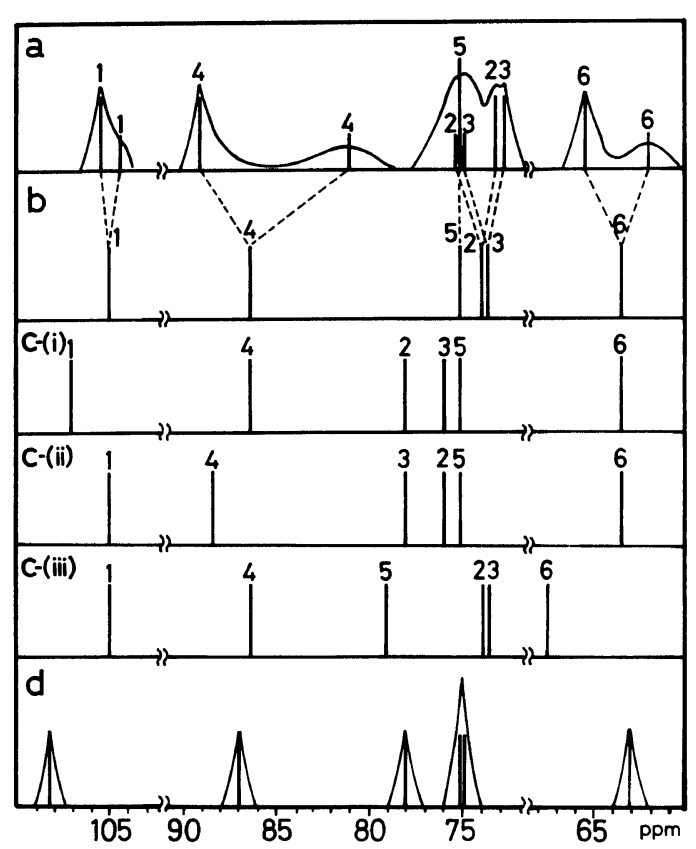

Figure 3. Schematic representation of $\mathrm{CP} / \mathrm{MASS}{ }^{13} \mathrm{C}$ NMR spectra. a, cellulose I experimentally observed; $b$, alkalicellulose when selective coordination of the sodium ion does not occur; c-(i), alkalicellulose with selective coordination of the sodium ion at $\mathrm{C}_{2}$; c-(ii), alkalicellulose with selective coordination of the sodium ion at $\mathrm{C}_{3}$; c-(iii), alkalicellulose with selective coordination of the sodium ion at $\mathrm{C}_{6}$; $\mathrm{d}$, aged alkalicellulose (AC-1a), experimentally observed.

the $\alpha$ and $\beta$ positions from the hydroxyl groups selectively coordinating with $\mathrm{Na}^{+}$ must diminish. Thus, the $\alpha$ and $\beta$ carbon NMR peaks must shift towards to a lower magnetic field, compared with the corresponding carbon peaks when the above-mentioned selective coordination of $\mathrm{Na}^{+}$is not considered. Of course, the degree of cationization of $\alpha$ carbon is larger than that of $\beta$ carbon. For the form (a) shown in Figure 2, $\mathrm{C}_{2}$ carbon might be considerably cationized as well as the $\mathrm{C}_{3}$ carbons. In this connection, the degree of cationization of $\mathrm{C}_{1}$ carbon is larger than that of the $\mathrm{C}_{3}$ carbons, because in alkalicellulose, the remaining $\mathrm{O}_{3}-\mathrm{H} \cdots \mathrm{O}_{5}^{\prime}$ intramolecular hydrogen bonding, before-mentioned, may anionize the $C_{3}$ carbon. By analogy, for the form (b), the $\mathrm{C}_{3}$ carbon is considerably cationized and $\mathrm{C}_{2}$ and $\mathrm{C}_{4}$, slightly cationized. For the form (c), the $\mathrm{C}_{6}$ and $\mathrm{C}_{5}$ carbons are cationized. Thus, corresponding to the forms shown in Figure 2, the $\mathrm{C}_{1}, \mathrm{C}_{2}, \mathrm{C}_{3}, \mathrm{C}_{4}, \mathrm{C}_{5}$ and $\mathrm{C}_{6}$ carbon NMR peaks must shift towards a lower magnetic field, compared with the corresponding carbon peaks when the abovementioned selective coordination of $\mathrm{Na}^{+}$is not considered. Figure 3 a shows a schematic representation of the CP/MASS ${ }^{13} \mathrm{C}$ NMR spectrum of cellulose I, experimentally determined and Figure $3 \mathrm{~b}$ shows a hypothetical spectrum of alkalicellulose $\mathrm{I}$ having an $\mathrm{O}_{3}-$ $\mathrm{H} \cdots \mathrm{O}_{5}^{\prime}$ intramolecular hydrogen bond when the effect of the coordination of $\mathrm{Na}^{+}$is not considered. Figure 3c-(i), (ii), and (iii) show hypothetical line spectra of alkalicelluloses, having the chemical structure shown in Figure $2 a, b$, and $c$, respectively. A comparison of these spectra with the spectrum in Figure $3 \mathrm{~b}$, shows 1) the $C_{1}, C_{2}$, and $C_{3}$ carbon peaks to be located in lower magnetic fields when $\mathrm{Na}^{+}$ coordinates to the hydroxyl group at $\mathrm{C}_{2}$ position (Figure 3c-(i)), 2) all $\mathrm{C}_{2}, \mathrm{C}_{3}$, and $\mathrm{C}_{4}$ carbon peaks for alkalicellulose when $\mathrm{Na}^{+}$is assumed to coordinate to the hydroxyl group at $\mathrm{C}_{3}$ position to shift towards a lower magnetic field (Figure 3c-(ii)), and 3) the $\mathrm{C}_{5}$ and $\mathrm{C}_{6}$ carbon peaks also to shift towards a lower magnetic field when $\mathrm{Na}^{+}$coordinates to the hydroxyl group at the $\mathrm{C}_{6}$ position (Figure 3c(iii)). The degree of this shift is expected to be greater for $\alpha$ carbons than $\beta$ carbons. Figure $3 \mathrm{~d}$ shows a schematic spectrum, experimentally observed for sample AC-1a. A comparison of Figure 3d with Figure 3c-(i), (ii), and (iii) indicates that selective coordination of $\mathrm{Na}^{+}$to the hydroxyl group at $\mathrm{C}_{2}$ (Figure 2a) is the most probable.

Summarizing, in an aged alkali cellulose solid, the molecular motion is relatively rapid, as compared with a cellulose solid and has intramolecular hydrogen bondings and a sodium ion selectively coordinates to the hydroxyl oxygen at the $C_{2}$ position of cellulose. 


\section{REFERENCES}

1. K. Kiessig, H. Hess, and H. Sobue, Z. Phys. Chem., 43, 309 (1939).

2. J. O. Warwicker, "Cellulose and Cellulose Derivatives," Part IV, N. M. Bikales, L. Segal Eds, John Wiley \& Sons Inc., New York, N. Y., 1971, Chapter XIII-H, p 325.

3. J. Hayashi, T. Yamada, and S. Watanabe, Sen-i Gakkaishi, 30, T-190 (1974).

4. J. Hayashi and T. Yamada, Nippon Kagaku Kaishi, 544 (1975).
5. K. Kamide, K. Okajima, T. Matsui, K. Kowsaka, and S. Nomura, Polym. Prepr., Jpn., 33, 589 (1984).

6. K. Kamide, K. Okajima, T. Matsui, and K. Kowsaka, Polym. J., 16, 857 (1984).

7. J. Schröter, J. Kunze, and B. Philipp, Acta Polymerica, 32, 732 (1981).

8. J. Kunze, A. Ebert, B. Schröter, K. Frigge, and B. Philipp, Polym. Bull., 5, 399 (1981).

9. W. Brown and R. Wikstrom, Eur. Polym. J., 1, 1 (1965).

10. K. Kamide, K. Okajima, K. Kowsaka, and T. Matsui, Polym. J., 17, 701 (1985). 